International Journal of Applied Engineering

Research and Development (IJAERD)

ISSN (P): 2250-1584; ISSN (E): 2278-9383

Vol. 11, Issue 1, Jun 2021, 27-48

(C) TJPRC Pvt. Ltd.

\title{
IMPROVEMENT IN THE REGRESSION RATES OF PARAFFIN BASED PROPELLANT
}

\section{JHUMKI NANDY \& GANDHAN RAM VISHAL}

Nitte Meenakshi Institute of Technology, P.B.No. 6429, Yelahanka,Bengaluru, India

ABSTRACT

The hybrid rocket has been in use due to a high level of safety and lower cost than the conventional solid and liquid rocket. Hybrid rockets are much more reliable than solid and liquid propellant rockets.Rockets based upon hybrid propellants suffer some disadvantages like poor burning rates of the fuel and inefficient combustion of the fuel.The solution was sought in the use of low melting solid fuel like paraffin wax. A total of eight compositions of fuels were processed using paraffin wax, stearic acid Araldite, hardener, LDPE, EVA, and carbon black. A total of eight compositions of fuels were processed using paraffin wax, stearic acid Araldite, hardener, LDPE, EVA, and carbon black. These fuel compositions were subjected to stress-strain analysis using Universal Testing Machine. Based on mechanical strength, three samples i.e. wax, one which has lower mechanical strength and one has higher mechanical strength were further studied for calorific value and regression rate. The calorific value was determined by the bomb calorimeter. The regression rate was evaluated by using a head-end injection test motor in which a swirl injector was used to feed the oxygen at an injection pressure of 300 p.s.i and 480 p.s.i. For the fuel Grain Composition-Paraffin Wax having initial web thickness- $39.26 \mathrm{~mm}$ at the oxygen injection pressure- 300 p.s.i and with burning duration 6.071 sec the average regression rate was found $5.06 \mathrm{~mm} / \mathrm{sec}$. For the fuel grain composition-Paraffin wax +Stearic Acid+ Araldite+ Hardener+ Carbon Black having initial web thickness- $39.15 \mathrm{~mm}$ at oxygen injection pressure 300 p.s.i and with firing duration $5.03 \mathrm{sec}$ the average regression rate was found $5.36 \mathrm{~mm} / \mathrm{sec}$. For the fuel grain composition Paraffin wax + Stearic Acid+ Araldite+ Hardener+ LDPE+ EVA+Carbon Black having initial web thickness- 37.5 mm at oxygen injection pressure- 300 p.s.i and firing duration $4.625 \mathrm{sec}$ the average regression rate $4.10 \mathrm{~mm} / \mathrm{sec}$. For the fuel Grain Composition-Paraffin Wax having initial web thickness- $38.63 \mathrm{~mm}$ at the oxygen injection pressure- 480 p.s.i and with burning duration $5.16 \mathrm{sec}$ the average regression rate was found $5.48 \mathrm{~mm} / \mathrm{sec}$. For the fuel grain composition-Paraffin wax +Stearic Acid-Araldite+ Hardener + Carbon Black having initial web thickness 39.03 at oxygen injection pressure 480 p.s.i and with firing duration $5.20 \mathrm{sec}$ the average regression rate was found $6.14 \mathrm{~mm} / \mathrm{sec}$. For the fuel grain composition Paraffin wax + Stearic Acid + Araldite +Hardener +LDPE +EVA +Carbon Black having an initial web thickness of $38.33 \mathrm{~mm}$ at oxygen injection pressure 480 p.s.i and firing duration 3.92 sec the average regression rate 5.05 $\mathrm{mm} / \mathrm{sec}$. For every composition of fuels the local regression rate, average regression rate, and mass consumption rate of all the fuel composition were examined through test firing and presented in this work. The increasing value of the injection pressure directly increased the burning rate of the solid fuel which results in progressive burning. The composition of the fuel directly controlled the regression rates. It has been observed that the composition which has higher mechanical strength has a lower regression rate and that with lower mechanical strength has a higher regression rate.

KEYWORDS: Paraffin Wax, Stearic Acid, Low-Density Polyethylene, Ethylene Vinyl Chloride, Young Modulus, StressStrain Curve \& Hybrid Propellant

Received: Mar 19, 2021; Accepted: Apr 09, 2021; Published: May 17, 2021; Paper Id.: IJAERDJUN20214 


\section{INTRODUCTION}

Thrust is produced by the ejection of hot gases from the burnt propellant. The propellant is a stored solid charge in the rocket chamber.Appreciated conventional rocket propulsion systems have been categorized depending on the type of the stored charge within the combustion chamber. Chemically reacted rockets are classified into three categories solid, liquid, and hybrid. Nuclear and solar rocket is the type of different energy sources. The basic function of the chemical rockets are (booster stage, sustainer), attitude control, orbit station keeping, etc.). According to the physical state of the propellant, chemical rockets are further classified as solid propellant rockets, liquid propellant rockets, and hybrid propellant rockets. The present era of rocket application is dominated by solid and liquid propellant rockets. But, both solid and liquid propellant rockets suffer from several disadvantages and demerits such as the use of high energetic propellant ingredients, ease of thrust modulation, start-stop, and restart operation. Hybrid rockets became the best solution to all the problems. In hybrid rocket propulsion systems, oxidizers and fuel are kept apart in different physical stages. Hybrid propulsion systems most commonly use liquid oxidizers and solid fuel. But sometimes, hybrid propulsion systems liquid fuel and solid oxidizer. The propellant and gaseous or liquid oxygen are kept separately within the motor with possible combinations such as solid fuel-liquid oxidizer or solid oxidizer-liquid fuel. Examining based on performance, hybrid propulsion system yield the density specific impulse of $514 \mathrm{gm}-\mathrm{sec} / \mathrm{cm}^{3}$ as compared to the best known solid propulsion system, which produces density specific impulse around $473 \mathrm{gm} \mathrm{sec} / \mathrm{cm}^{3}$, and best known liquid propulsion system, which yields the density specific impulse $192 \mathrm{gm}$. sec/ $\mathrm{cm}^{3}$. The comparison made above clearly shows that the hybrid propulsion system has an edge over its solid and liquid counterparts.

Earlier time at the beginning hybrid combustion model was introduced by Bartel \&Rannie ${ }^{1}$. The 1-D gaseous tube-like model was considered. Flame behavior was not predicted by the researchers but by diffusion controlling factor, the diffusing phenomena of oxygen molecules were studied. Penner ${ }^{2}$ gives the postulations about burning rate diffusion control, and the functional relationship between the axial and radial concentration of oxygen is given by the linear equation.

$$
\frac{\partial K_{o}}{\partial x}=\left(\frac{D}{u}\right)\left[\frac{\partial^{2} K_{o}}{\partial r^{2}}+\left(\frac{1}{r}\right) \frac{\partial K_{o}}{\partial r}\right]
$$

Leo Green $\mathrm{Jr}^{3}$ produced a burning hybrid system that exhibits slow-burning depends on the definition of Spalding's mass transfer number with Chilton-Colburn modified model to achieve Reynold's model analogy between mass \&momentum transfer.

Houser \& Peck ${ }^{4}$ proposed a new combustion model with a hollow cylindrical shape of grain within the flow of gaseous oxygen stream. Karabeyuglu ${ }^{5}$ et al, proposed the combustion model with an unstable liquid melted layer which possesses three stages of burning. In the first stage started the formation of the liquid layer above the solid grain upper surface, the second stage low viscous liquid layer formation with appropriate linear stability, and in the third stage entrainment of liquid droplet fuel into gaseous oxygen stream. 


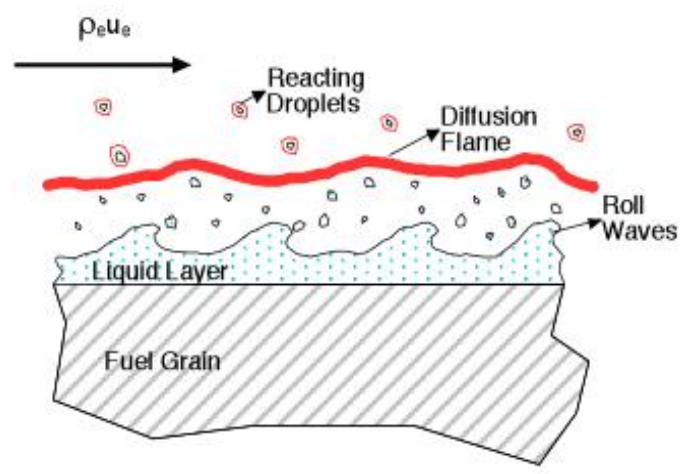

Figure 3: liquid Layer Instability.

The flat plate combustion model was introduced by Marxman ${ }^{6}$ which resembles with diffusion flame model with strong turbulence. In this type of combustion model, diffusion flame was formed within the boundary layer. The fuel molecules as soon as flow to the boundary layer the solid charge present in the fuel surface absorbs heat from the boundary layer and another side gaseous oxygen diffused to the boundary layer. The proper mixing process was started within the boundary layer zone and a flame will be produced. The boundary layer is comprised of two zones. The upper zone constituted with propagating flame zone in which temperature and velocity profile gradient rising will be in the opposite direction. The lower zone is situated under the propagating fame zone where the velocity and temperature gradient profile increment will be in the same direction.

A pressure-sensitive hybrid charged model was introduced by Ramohalli, Stickler ${ }^{7}$ in which depolymerized small pieces of fuel degraded from the surface at a particular regression rate. The depolymerized surface with active species reacted thermally. Estey et $\mathrm{al}^{8}$ found that in the combustion model the term regarding radiant heat transfer including radiation equation empirically improved the result. On the other side, the convective heat transfer model is much more pronounced for hydrocarbon fuels.

Sarigul-Klijn et $\mathrm{al}^{9}$ shown in their model the advantage of storage of hybrid propellant within the hybrid rocket motor by using cold nitrous-oxide. This cold oxidizer is brought into the inner casing of the motor by the turbo-pump system. Nitrous oxide is at $-100^{\circ} \mathrm{F}$ temperature, highly dense, required less tank volume and less weight. Fuel burnt under a higher oxidizer ratio. With this type of oxygen system arrangement, motor case weight will be minimal which will contribute to the reduced size of the motor. With higher oxidizer and fuel-burning will result in a reduced amount of propellant sliver which will reduce overall propellant residual weight.

Rocket engine with enhanced oxidizer proposed by Eric J. Jacob ${ }^{10}$. The problem of the fuel entrainment into the gaseous stream of oxygen and improper mixing results in the poor performance mostly used in the hybrid rocket combustion mechanism. The solid oxidizer mixing mechanism within the combustion zone similar to solid fuel combustion but the proper mixing can be possible at stoichiometric conditions. A hybrid propellant-based rocket motor will not face any unsafe characteristics with less rapid combustion reaction. Safety measures were taken into consideration with the purely experimental investigation since solid oxidized was used in this study with the fuel.

Practically the design study optimization with HTPB/LOX in hybrid rocket application was proposed by Cangjiin Lee et $\mathrm{a}^{11}$ for the air-launch system with the first stage. By this investigation shown, the advantage of the use of hybrid propellant over solid rocket propellant with an average specific impulse of 350sec.Different variable parameters like port design, initial oxidizer flux, inside chamber pressure, and area ratio of the nozzle shown the design optimization on the 
same length of the hybrid rocket motor.From this investigation, it was proposed that the optimized result provides nearly the same design of length of the engine.

Several techniques were adopted by Karabeyoglu et al ${ }^{12}$ to improve the regression rates of the hybrid fuel by using a swirl injector, adding different self-oxidizing and self-decomposed solid particles. Incorporating solid oxidizing particles in the solid fuel produced the surface roughness which will burn progression than the conventional matrix structured fuel.

Progressive regression of the hybrid solid fuels with discharged combusted hot smokes by portable visible spectrometers was studied by Edmonal W. Wilson and Jr Brett D. Keller. ${ }^{13}$ In this work two types of spectrometers for visible range and ultraviolet range were used. With different fuel/ oxidizer ratios different hydroxyl radical spectrums were studied. Both in spatial and time coordinates regression rates were measured.

Moutet and Barrere ${ }^{14}$ adopted the results which were derived from different theoretical and experimental conclusions about different combustion models with melted fuel mechanism in the hybrid-based propellant problem. Emmos introduced the concept regarding thermodynamic parameters adopted also by the researchers. Spalding developed the proposed model of Emmos. In this investigation, the proposed combustion model is treated as a flat plate model with finite thickness. The finite amount of oxidizer and fuel was produced with this flat plate model assumption.

Karabeyoglu and Cantwell ${ }^{15}$ utilized the boundary conditions from Benjamin which is the extended theory of Craik. Underflow conditions a linearly unstable liquid gas interphase was observed from the boundary conditions. An empirical mass transfer correlation was constructed from the data of Gater and L'Ecuyer to deal with non-linearity. The model manifested the fact about the combustion model of the paraffin wax which has a low viscous liquid layer and greater amount of liquid droplet entrainment from the liquid-gas interface from the investigation of Cantwell, Karabeyoglu, and Altman. The greater amount of the entrainment of the fuel droplets will increase the regression rate to four and five times more than the conventional polymeric fuel. The reported analyzed burning model of hybrid rocket motor was evaluated by Green $\mathrm{Jr}^{16}$. The model was incorporated with different mechanical assumptions with different thermodynamic parameters. The analogical aspect between moment and mass transfer was given by early results of Bartel \& Rannie and this result can be generalized with Spalding's mass transfer number to predict the burning rate of slow-burning. The Plexi-glass oxygen system published experimental data without adjustment of empirical constants. Both laminar and turbulent flow behavior was taken into account in the duct flow by Fineman ${ }^{17}$. In this model mass transfer expression was proposed by Spalding in the stagnant film and a significant combustion theory has proposed. For this case, the thickness of the laminar flame which has produced in front of the duct is the thickness of the boundary layer. George et $\mathrm{al}^{18}$ was done series of experiments for regression rate enhancement with $\mathrm{HTPB} / \mathrm{GOX}$ system with the effects of addition of ammonium perchlorate (AP) and metal particles. The addition of a different proportion of AP/Al with different port diameters will enhance the regression rates. The exponents for oxidizer mass flux and port diameter were derived experimentally found different from other turbulent conventional diffusion-based flame theory. Kim et $\mathrm{al}^{19}$ investigated the combustion characteristics with $96 \mathrm{~mm}$ cylindrical multiport grain.

The investigation brought the effect of multiport grain on regression rate and the effect of the distance between the ports on the regression rate of the solid fuel.In this work, the number of 4 ports was improved the regression rates of the solid fuel. Many techniques were adopted to enhance the regression rate like the use of helical grains and the use of metallic wire inserted in the solid grain. 
Chiaverini \& $\mathrm{KuO}^{20}$ has introduced a discussion of all starting theories of hybrid rocket application in all aspect. With a diffusive mixing mechanism, the combustion process of evaporated fuel from an inert solid surface takes place with the vaporized oxidizer which was flowing through the port. The thickness of the flame zone with the location of the boundary layer is shown roughly to scale. The observed flame zone will be relatively deep in the boundary layer and the shape of the flame zone will be according to the theory of Marxman, Gilbert, Wooldridge, and Muzzy. The fuel-rich zone existed in the flame position and lower flam temperature was measured near the boundary layer. A series of experimental investigations were done by Tamura, T., Yuasa, S., and Yamamoto, K. ${ }^{21}$ for the optimization of swirl flow with PMMA based solid fuel under the gaseous oxygen stream and for enhancing the regression rate with different grain configurations. The helical-shaped grain was enhanced the regression rate up to 50 percent in this study. Paraffin wax-based solid fuel increased regression rates of two to three-time folds compared to conventional polyethylene fuel of ultra-high molecular weight.

In the case of a hybrid-based rocket system of a tested rocket motor, the combustion flow process was achieved through combustion chamber geometry, nozzle geometry, air-fuel flow rates, and properties of fuel and oxidizer. Zeldovich together with Novozhilov ${ }^{22}$ developed the method of solid-phase energy conservation which helped to derive the calculation strategy for transient solid propellant burning. The rate-limiting factor proportionately changes the diffusion of fuel molecules. The rate-limiting factor has the functional dependency of the heat transfer rate of the interacting zone between solid and gaseous components. In the case of hybrid combustion heat, the release rate was increased with the addition of energetic metal particles. These energetic metal particles contributed to increased heat release rate from the fuel surface by oxidizing itself which stabilize the velocity in the boundary layer but provided a more energetic interaction surface.

The experimental investigations on hybrid rocket motors were performed at I.G Farben in Germany by L. Andrussow. O. Lutz and W. Noeggerath ${ }^{23}$. The experiment was conducted with coal as a solid fuel and nitrous oxide as an oxidizer in a $10 \mathrm{KN}$ hybrid rocket motor. Due to the low sublimation rate coal was unburned and the hot-fire motor test was unsuccessful. General Electric company carried out the experiments with hypergolic propellants. The subsequent work was guided by E. J. Wernimont and S. D. Heister ${ }^{24}$. In this work polyethylene and 90percent hydrogen peroxide are used as a fuel and oxidizer. For the decomposition of hydrogen peroxide in the pre-combustion chamber, one silver screen catalyst bed was used. This catalyzed silver screen bed also ignites the polyethylene fuel. The researchers used the unique rod and tube grain design which caused grain crack, combustion insensitivity, and high combustion efficiency. From this investigation, it was concluded by the researchers that low regression rate due to insignificant entrainment of the fuel droplet to the oxidizer flow rate.

NASA Wallops, Standford University, and Space Propulsion Group (SPG) tried to do a flight test with liquefying fuel hybrid sounding rocket to an altitude of $100 \mathrm{~km}$. Jonny Dyer et al ${ }^{25}$ investigated withliquid nitrous oxide ad paraffin wax to get a $5 \mathrm{~kg}$ payload at a predetermined altitude. A series of sounding rocket was developed by Purdue University for the functional purpose of micro-gravity experimental instruments. In this application for intermediate altitude application hypergolic type of propellant like hydrogen peroxide with LDPE was used and a 4-port grain configuration was also used for this launch.

Eric Boyer ${ }^{26}$ did the investigation with the additives mixing with paraffin wax. In this investigation, the researcher added $10 \%$ of LiALH4 which was improved the regression rate from $7-10 \%$ over virgin paraffin wax as a fuel. With the 
addition of $10 \%$, LiAlH4 mass consumption rate at the time of burning also was increased than pure paraffin wax.

\section{SCOPE}

The hybrid propulsion system is much safer than the other rocket propulsion system because of these safety features and environmental advantages.It is a much more appreciable alternative fuel system for rocket operation; however, large-scale hybrids were being adopted but not commercially successful. The reason for choosing hybrids to get a new way over the traditional polymeric fuels is the traditional polymeric fuels evaporate very slowly, resulting in difficulties to generate thrust like solid and liquid propellant required for most of the applications. The problem of the low regression rate for the conventional polymeric fuel can be compensated by using paraffin wax as a solid fuel and the burning rate for paraffin wax is 3 and 4 times leads unstable, low viscous liquid film. Because the viscosity of the melted film layer above the main grain surface is low and the entrainment of the droplet will be quick from the unstable liquid film within the gaseous film of oxygen with the high speed of injected gaseous oxygen.

One of the major shortcomings of paraffin wax fuel grain is its poor mechanical strength. The present work is directed towards an tried to improve the mechanical strength of paraffin wax by adding some stiffening additives like stearic acid, low-density polyethylene, ethylene-vinyl acetate copolymer in a small percentage and then study. Fuel grains were made of three compositions for further study of combustion characteristics in a stream of gaseous oxygen. To fulfill the above goal the experimental work was carried out in the following direction.

\subsection{Design and Fabrication Work}

\subsubsection{Combustion Chamber}

In this present study, a mild steel hollow flanged cylinder was used as a combustion chamber of the test motor. The internal diameter of the combustion chamber is $79 \mathrm{~mm}$, an outer diameterof $91.8 \mathrm{~mm}$, length of $275.4 \mathrm{~mm}$. At either end of the chamber, flanges of $168.5 \mathrm{~mm}$ diameter were welded. The head-end flange is $23 \mathrm{~mm}$ thick whereas the nozzle-end flange is $20 \mathrm{~mm}$ thick. Six holes of $14 \mathrm{~mm}$ diameter have been made at equidistance on both of the flanges at $128.1 \mathrm{~mm}$ p.c.d to attach the injector and the nozzle respectively.

The hollow cylindrical-shaped fuel grain within the combustion chamber was directly cast and oxygen gas was directly injected into the port while the combustion takes place.

\subsubsection{Injector}

In the present study, the swirl injector was used for feeding the gaseous oxygen into the combustion chamber. The injector consists of a hollow cup of inner length $25 \mathrm{~mm}$ and a diameter $40 \mathrm{~mm}$ and a centrally fitted tapered cylindrical block of length $30 \mathrm{~mm}$, maximum diameter $39 \mathrm{~mm}$, and minimum diameter $30 \mathrm{~mm}$. This arrangement gives the oxidizer outlet area about $62 \mathrm{~mm}^{2}$. A $5 \mathrm{~mm}$ diameter hole was made tangentially at a distance of $5 \mathrm{~mm}$ from the top for letting the oxidizer. Proper piping was attached to an oxygen inlet hole for connecting the injector to the oxygen supply line. This injector was welded centrally to the injector plate of diameter $168.5 \mathrm{~mm}$ and thickness $10 \mathrm{~mm}$. Six holes of the equivalent diameter of $14 \mathrm{~mm}$ were made at a pitch circle diameter of $128.1 \mathrm{~mm}$ to fit the injector to the combustion chamber. In the plate.3.4 inlet and outlet side of swirl injector have been shown. In the fig.3.3 line diagram of swirl, the injector has been shown.

\subsubsection{Nozzle}

A water-cooled straight cone convergent-divergent nozzle was used in the present investigation. The nozzle was used for 
this investigation with the converging angle of $45^{0}$ whereas the divergent angle of $15^{0}$ was selected for this study. Nozzle's total length was $66.7 \mathrm{~mm}$ with an exit diameter of $26.06 \mathrm{~mm}$. The maximum convergent side diameter of $79.4 \mathrm{~mm}$ was the matching diameter exactly like the diameter of the combustion chamber.

Wall thickness for the conventional C-D was $5 \mathrm{~mm}$. It has a flange of diameter $110 \mathrm{~mm}$ and a thickness of $20 \mathrm{~mm}$ at the end of the convergent section to attach the nozzle to the combustion chamber. This attachment between the nozzle \& combustion chamber was made by fixing a retainer ring matched with the shape of the nozzle of diameter $168.5 \mathrm{~mm}$ and having six holes at equal distance of diameter $14 \mathrm{~mm}$ at p.c.d $128.1 \mathrm{~mm}$ attached with nuts and bolts. A hollow cylindrical section of diameter $90 \mathrm{~mm}$ and thickness $10 \mathrm{~mm}$ was welded around this nozzle. Provisions were made in it for in-letting and out-letting the water in the vacant space between the nozzle and the cylinder. The water was fed into it with the help of a $0.25 \mathrm{hp}$ water pump. The nozzle area ratio is 7.In plate.3.6 the water-cooled nozzle assembly has been shown. In fig 3.5 the schematic diagram of the nozzle and nozzle retainer ring has been shown.

\section{DESIGN AND FABRICATION OF MOULD \& MANDREL}

After deciding the grain configuration, the second most important step is to design a mould to get the fuel grains in the required shape and dimension. The mould assembly was fabricated from aluminum. The main mould was made from an aluminum tube of length $300 \mathrm{~mm}$, outer diameter $88 \mathrm{~mm}$, and inner diameter $76-77 \mathrm{~mm}$. The inner wall was slightly tapered for easy removal of grain. The bottom end was closed by a thread-fitted cylindrical cup.

\subsubsection{Hollow Cylindrical Fuel Grain Design}

The moulded shape of the solid grain with a densified mass of processed solid material within the combustion chamber. It is a very common finding regarding hybrid fuel regression rate and mass consumption rate are time-dependent parameters that not only alter the performance but also affect the efficiency of the motor. A proper design of fuel grain would be helpful to some extent to maximize efficiency and minimize the wastage of fuel. Once ignited, fuel grain burns from the surface of all sublimated fuel to generate hot gases that are expelled through the nozzle.In the present work, it was decided to design the grain of cylindrical configuration as it's inside the cross-sectional area is constant along the axis of the combustion chamber. The processed fuel was burned in the head end injection of a hybrid rocket motor using a swirl injector for introducing gaseous oxygen into the combustion chamber. The outside diameter of the hollow cylindrical grain was $70 \mathrm{~mm}$, the opening of the port was $30 \mathrm{~mm}$ and the total length of the grain was $200 \mathrm{~mm}$. In plates $3.9,3.10$, and 3.11 the grains of composition-1, composition-2, and composition-3 have been shown.

\subsection{Fuel Ingredients}

\subsubsection{Paraffin Wax}

Wax is a plastic-like material that is organic and is of solid form in the ambient temperature. With the increment in temperature, it is melted intoa liquid. Since wax is plastic in nature it has deformed under the pressure without any essence presence of heat.

The general features are listed below:

- Thermo-plastic in nature

- Combustible

- Liquid at $45^{\circ} \mathrm{C}$ to $95^{\circ} \mathrm{C}$ 
- Insoluble in water

\subsubsection{Stearic Acid}

Stearic acid supplied by $\mathrm{CDH}$ was used in the present work. Its molecular formula is $\mathrm{C}_{18} \mathrm{H}_{36} \mathrm{O}$ and the molecular weight is $284.5 \mathrm{gm}$. It is a hard white or faintly yellowish crystalline solid.

\subsubsection{Epoxy Resin}

Epoxy resin is a molecule with a repetitive epoxy group, which can be hardened to a low grade of plastic. The presence of the glycidyl group in epoxy is responsible for the characteristics of the glycidyl and such a name given to this type of resin. This grey, thixotropic adhesive has been developed to achieve a handling strength after $1 \mathrm{~h}$ at room temperature (253C). The high functionality of the resins increases crosslink density and improves thermal stability and chemical resistance. Cures with negligible shrinkage and without releasing volatiles.

\subsubsection{Epi-Chlorohydrin: (hardener)}

The hardener used in this investigation is Epi-chlorohydrin which is yellow, volatile, and flammable. It emits toxic fume when heated to decomposition in a large amount. Epi-chlorohydrin is partially soluble in water but highly miscible with alcohol, ether, chloroform, trichloroethylene, and carbon tetrachloride. Epi-chlorohydrin is insoluble in petroleum-based hydrocarbons. The hardener used for this study was of commercial grade with $98 \%$ purity with a maximum of $02 \%$ of water.

\section{EVA-COPOLYMER}

EVA-copolymer is with high flowability, high flexibility, elasticity, and thermal stability due to the presence of high content VA. EVA has good compatibility with paraffin wax, good low-temperature resistance, and non-toxic. EVA possesses good adhesive strength with other materials when it will be in the hot melted phase. It possesses excellent heat stability.

\subsubsection{LDPE: $\left(\mathrm{C}_{2} \mathrm{H}_{4}\right)_{\mathrm{n}} \mathrm{h}_{2}$}

Low-density polyethylene is polymer under the thermoplastic category consisted of long hydrocarbon chains.. Glass transition temperature of paraffin wax is depending on the crystalline structure of the polyethylene. The melting point also depends on the crystalline structure of polyethylene. Since glass transition temperature and melting point are crystalline structure dependent, these two parameters can not be always observable. Commercially used long-chain-based polyethylene and short-chain-based polyethylene, a typical range of the melting point are $120^{\circ} \mathrm{C}-130^{\circ} \mathrm{C}$ and $105^{\circ} \mathrm{C}-115^{\circ} \mathrm{C}$ respectively.

\subsection{Mixing Procedure of Propellant Ingredients}

The following three compositions were formulated using the above chemicals in different proportions for combustion study.

Table 1: Composition of Three Samples

\begin{tabular}{|l|l|l|}
\hline \multicolumn{1}{|c|}{ Sample No - 1 } & \multicolumn{1}{c|}{ Sample -2 } & \multicolumn{1}{c|}{ Sample -3 } \\
\hline Paraffin Wax (100\%) & Paraffin Wax (85.47\%) & Paraffin Wax (78.36\%) \\
\hline------- & Stearic Acid $(8.54 \%)$ & Stearic Acid(7.38\%) \\
\hline------- & Araldite(4.2\%) & Araldite(3.91\%) \\
\hline
\end{tabular}




\begin{tabular}{|l|l|l|}
\hline-------- & Hardener(0.85\%) & Hardener(0.78\%) \\
\hline------- & Carbon Black(0.85\%) & LDPE $(4.04 \%)$ \\
\hline------ & $---\cdot---$ & EVA(4.04\%) \\
\hline------ & ------- & Carbon Black $(1.01 \%)$ \\
\hline
\end{tabular}

Composition-I was prepared by melting the required quantity of wax at $65-70^{\circ} \mathrm{C}$ with continuous stirring. The mixture was cast in a steel-made mould to get the required shape and size of the grain.

The following procedures were followed for composition-II

\section{Composition-II:}

- Melt the required quantity of wax at $60-70^{\circ} \mathrm{C}$.

- Melt the required quantity of stearic acid separately at $56-60^{\circ} \mathrm{C}$ using a water bath.

- Mix the melted wax and stearic acidwith continuous mixing and heating in the water bath till the mixture becomes uniform.

- Mix the required quantity of Araldite and hardener in 5:1 proportion.

- Pouring the mixture of Araldite and hardener in the above mixture at a temperature around $60^{\circ} \mathrm{C}$.

- Mix the required quantity of carbon black.

The following procedure was applied to prepare the Composition - III:

- Melt the wax at $60-70^{\circ} \mathrm{C}, \mathrm{LDPE}$ at $110-120^{\circ} \mathrm{C}$, and mixed both at $140^{\circ} \mathrm{C}$ with regular stirring.

- Heat the quantity of EVA to $140^{\circ} \mathrm{C}$ and mixed it with the melted wax-LDPE mixture for $1 \mathrm{hr}$ for blending at the temperature of about $120^{\circ} \mathrm{C}$.

- Mixed the melted stearic acid with melted paraffin wax-LDPE-EVA properly and blended it with paraffin wax LDPE-EVA slowly kept in a water bath.

- Pouring the mixture of Araldite and hardener (5:1) slowly and carefully in the above mix and finally add the carbon black in installment with regular stirring.

- The fuel mixture as obtained after mixing of the ingredients was cast in the clean mould and kept for curing first at low temperature and then at ambient temperature for $3 \mathrm{hrs}$.

\subsubsection{Igniter}

The shellac igniter is known as a pyrotechnic ignitor which was made by Shellac powder of $20 \%$ by weight, hydrolyzed shellac taken by the amount of $5 \%$ of the total weight of the composition, $\mathrm{NH}_{4} \mathrm{ClO}_{4}$ (ammonium perchlorate) of $75 \%$, and $\mathrm{Fe}_{2} \mathrm{O}_{3}$ (ferric oxide) of 3 gmfor the current investigation.

A shellac bead was considered as an initially charging igniter with a primary charge igniter with the three-round coil of $5 \mathrm{~mm}$ and length of $10 \mathrm{~cm}$ of 34 SWG nichrome wire. These three rounded coils are connected to the outside electrical source by a long copper wire. For this investigation, the initially used primarily based charged igniter of the shape of a bead around a three-round coil of diameter $5 \mathrm{~mm}$ and length $10 \mathrm{~cm}$ of $34 \mathrm{SWG}$ nichrome wire. The ends of the coil were soldered with long enameled copper wires for electrical connection. The secondary igniter was made with the 
powder form of the above composition. Approximately four grams of powder was filled in a polythene bag of size $6 \mathrm{~mm} \times$ $2.5 \mathrm{~mm}$ and the primary igniter was inserted in it. The bag was tightly closed with the help of adhesive tape. The ignition delay of this igniter was found to be $2.00 \mathrm{sec}$ and they were found satisfactory for the static testing of the hybrid motor.

\subsubsection{Inhibitor}

The inhibitor was applied as a thermal insulator on the outer surface of the grain and the inner wall of the motor. The hollow cylindrical grain in this investigation was kept inside. The inhibitor was made with Araldite resin, hardener, and chalk powder in the ratio of 20:1:30. Due to the use of the inhibitor heat was not transferred from the grain surface to the motor wall and intact the grain in the motor. After the application of the inhibitor, the grain was kept for $12 \mathrm{hrs}$ for the curing of the inhibitor.

\section{Test Procedure}

The following procedures were carried out for the static test firing:

- The cylindrical-shaped grain was loaded in the motor.

- The igniter was placed at the head end of the grain already loaded in the combustion chamber and its terminal wires were taken out through the nozzle end to connect them with the ignition unit.

- $\quad$ The injector plate was fitted at the head end of the chamber with the help of bolts and nuts.

- The nozzle was fixed with the help of a nozzle retaining ring at the downstream end of the combustion chamber.

- Gas line of the oxygen connected to the adapter at the inlet port of the injector \& the prototype motor was mounted on the static testbed.

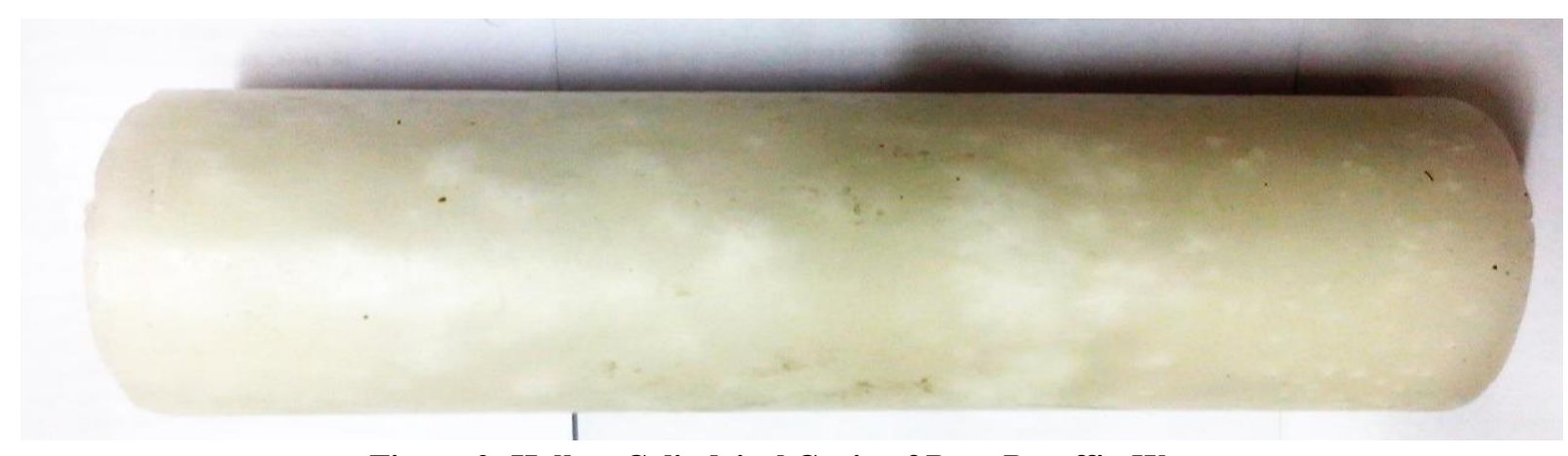

Figure 2: Hollow Cylindrical Grain of Pure Paraffin Wax.

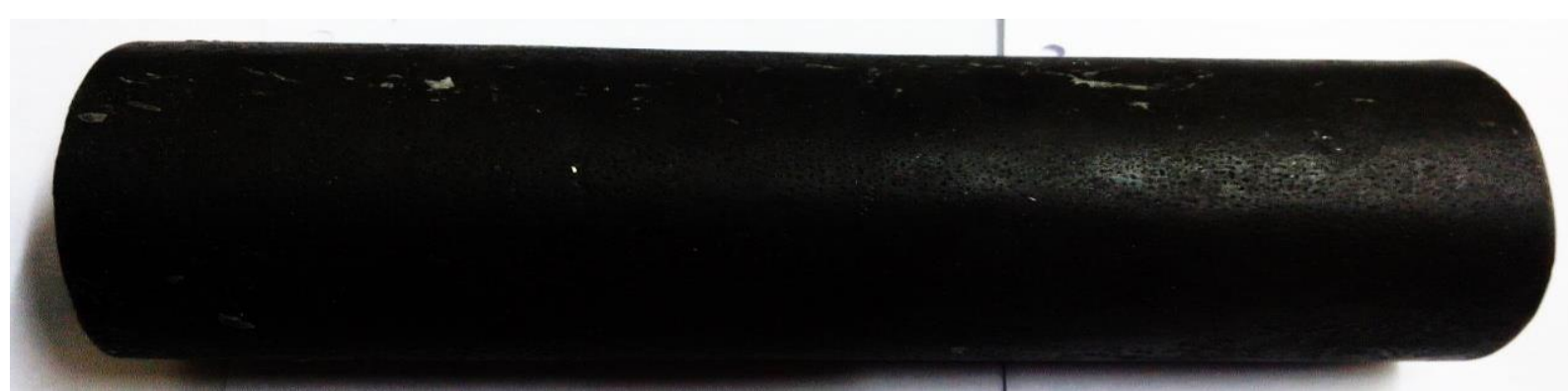

Figure 3: Hollow Cylindrical Grain of the Composition 1. 


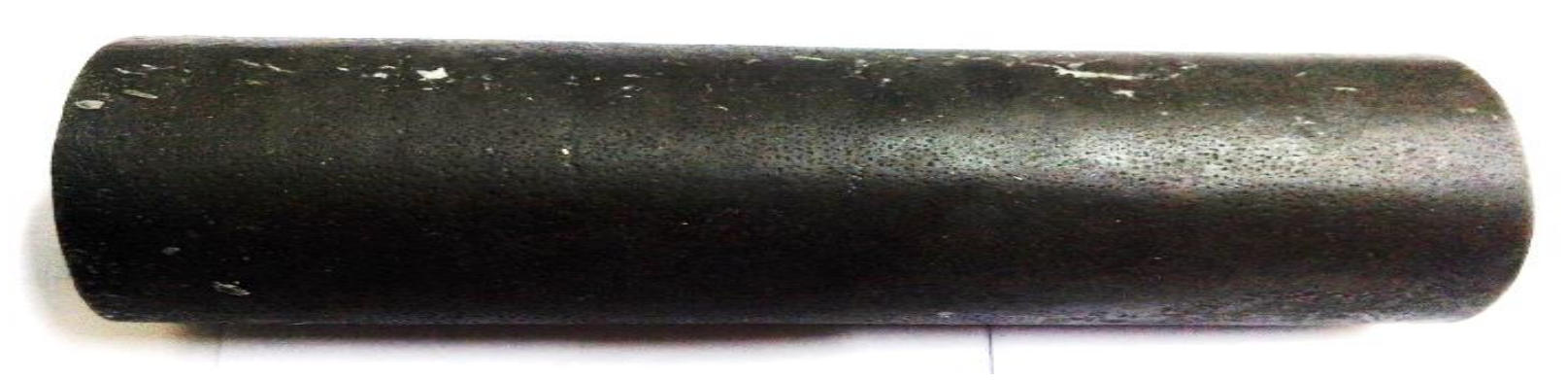

Figure 4: Hollow Cylindrical Grain of the Composition 2.

\section{RESULT}

\subsection{Heat of Combustion Measurement}

The adiabatic Bomb Calorimeter used to find the calorific value of the compositions:Composition-1: Pure Paraffin Wax (100\%), Composition-2: Paraffin Wax (85\%)-Stearic Acid (8.5\%)- Araldite (4.2\%)-Hardener (0.85\%)-Carbon Black (0.85\%), Composition-3Paraffin Wax (78.36\%)-Stearic Acid (7.8\%)- Araldite (3.9\%)-Hardener (0.78\%)-Carbon Black (1\%)-LDPE(4\%)-EVA(4\%).

The following relations were used for this purpose:

$$
\mathbf{W}=\frac{m \times H_{m}}{\Delta T}
$$

where $\mathrm{W}=$ water equivalent or the energy equivalent of the calorimeter, $\mathrm{m}=$ weight of benzoic acid in $(\mathrm{gm}), H_{m}=$ heat of combustion of benzoic acid in (cal/gm), $\Delta \mathrm{T}=$ temperature rise.

$$
\Delta H_{\mathrm{f}=}^{\mathbf{0}} \frac{\text { Temperaturerise } \times \text { waterequivalentof thecalorimeter }}{\text { weightof thesample }}
$$

The water equivalent of the calorimeter was evaluated by burning a known quantity of (about 1 gm) of benzoic acid in the oxygen at 400 p.s.i. The water equivalent of the bomb calorimeter used in the present work was found to be $2371.74 \mathrm{cal} /{ }^{\circ} \mathrm{c}$. The calorific values of the above-mentioned compositions obtained in the present work are the following:

$$
\begin{aligned}
& \left(\Delta H_{\mathrm{f}}^{0}\right)_{\text {composition-1 }}=11,362.840 \mathrm{Kcal} / \mathrm{Kg} \\
& \left(\Delta{H_{\mathrm{f}}^{0}}_{{ }_{\text {composition-2 }}}=11,513.38 \mathrm{Kcal} / \mathrm{Kg}\right. \\
& \left(\Delta H_{\mathrm{f}}^{0}\right)_{\text {composition-3 }}=11,362.84 \mathrm{Kcal} / \mathrm{Kg}
\end{aligned}
$$

\subsection{Regression Rates for the Fuels Grains}

The most unavoidable problem with conventionally appreciated hybrid propellant-based rocket has a poor burning rate. Thus a poor volumetric loading of the fuel to obtain the required mass flow from the rocket motor. The problem was solved to some extent by the introduction of low-temperature melting fuel such as paraffin wax or cryogenic fuels like solid carbon monoxide. However such fuels lack sufficient mechanical properties to withstand the harsh condition of transportation and take-off. A solution was needed for the betterment of the mechanical properties of these compositions of these fuels.

In this study, the main motto was to enhance the mechanical strength of the virgin paraffin wax using different 
additives like stiffening agent stearic acid, Araldite, hardener, and other polymers in small proportion. A total of eight compositions were formulated using the above ingredients. From these formulations, the following three compositions were subjected to regression ratestudy in a stream of gaseous oxygen using a head-end injection hybrid test motor to evaluate the relative regression rate of three formulations.

The cylindrical port burning fuel grains of dimensions length-200 mm, O.D-68.5 mm, I.D-30mm were processed and test-fired at two different oxygen injection pressures for duration of about $5 \mathrm{sec}$.After the firings, the grains were taken out, cleaned \& weighed to evaluate the mass consumption rate in each case. The grains were cut lengthwise and unburned web -thickness was measured at each one $\mathrm{cm}$ distance to evaluate the local regression rate. The following equation was used for evaluating the local regression rate:

$$
\dot{r}=\frac{\text { Initialwebthickness }- \text { Finalwebthickness }}{\text { firingDuration }}=\frac{r_{i}-r_{f}}{t}
$$

Tables 2 to 7 are presented the locally varied regression rate at different stations of the grain along the length. Along the length of the grain, the average regression rate was found with average web thickness for composition1,composition2, composition 3 at 300 p.s.i and 480 p.s.i injection pressures mentioned in the table from 2 to 7 . Tables 8 and 9 presented the comparative study of the results of the average regression rates with fuel consumption rate by mass. Tables 2 and 3 present the local regression rate and fuel consumption rate at 300 p.s.i and 480 p.s.i injection pressure respectively. It was found that the regression increase with composition change in the order of sample-1> sample. $2>$ sample. 3 for both of the injection pressures. Further from the analysis of mechanical properties, it is seen that the tensile strength and young modulus for these samples are in order of sample.3> sample. $1>$ sample. 2 . It has been observed that the composition which has higher mechanical strength has a lower regression rate and vice versa. Increasing the oxygen injection pressure resulted in the high mass flux of the fuel.

Table- 8 presented the average regression rate and average mass consumption rate of the fuel at injection pressure 300 p.s. and for 480 p.s.iin table-9 respectively. The mass consumption rate has been observed higher for the composition of lower mechanical strength and lowers for the composition of higher mechanical strength.

Many parameters are responsible for different regression rates. Some of them like thermochemical properties of fuel and grain configurations are fuel-oxidant specific while others such as positioning of fuel grains in the combustion chamber, oxidizer feed system design and chamber pressure are operating condition specific. In the present experimentation, a swirl injector is used to feed the oxygen into the combustion chamber in which the fuel grain was located $3 \mathrm{~cm}$ away from the injector end. Table 10-15 are interpreted the results regarding port diameter, port area after burning, and injected oxidizer mass flux. With the same composition the port diameters were increased with the two applied injection pressure and as well as it has given the decrement in the port area also after burning with less oxidizer mass flow rate. Overall it can be included from these results that with higher injection pressure the firing duration can be reduced and the same composition with the same dimension will give a better regression rate which will improve the specific impulse.

\section{Fuel Grain Composition-Paraffin Wax}

Initial Web Thickness- $39.26 \mathrm{~mm}$

Oxygen Injection Pressure- 300 p.s. $i$ 
Table 2: Regression Rate Data for Composition-1

\begin{tabular}{|c|c|c|c|c|}
\hline \multirow[b]{2}{*}{ No. of Obs. } & \multirow[b]{2}{*}{ Station No. } & \multicolumn{3}{|c|}{ Composition-1 } \\
\hline & & $\begin{array}{c}\text { Average } \\
\text { Thickness in }(\mathrm{mm})\end{array}$ & $\begin{array}{c}\dot{r}_{\text {local }} \\
\text { in }(\mathrm{mm} / \mathrm{sec})\end{array}$ & $\begin{array}{c}\dot{\boldsymbol{r}}_{\text {avg }} \\
\text { in }(\mathrm{mm} / \mathrm{sec})\end{array}$ \\
\hline 1. & 0. & 4.41 & 5.74 & \multirow{11}{*}{5.07} \\
\hline 2. & 02. & 7.20 & 5.28 & \\
\hline 3. & 04. & 9.80 & 4.85 & \\
\hline 4. & 06. & 9.51 & 4.90 & \\
\hline 5. & 08. & 9.52 & 4.89 & \\
\hline 6. & 10. & 9.51 & 4.90 & \\
\hline 7. & 12. & 9.25 & 4.89 & \\
\hline 8. & 14. & 9.13 & 4.96 & \\
\hline 9. & 16. & 9.39 & 4.92 & \\
\hline 10. & 18. & 7.11 & 5.29 & \\
\hline 11. & 20. & 7.40 & 5.24 & \\
\hline
\end{tabular}

Initial Web Thickness- 39.15 mm

Oxygen Injection Pressure- 300 p.s.i

Firing Duration- 5.03 sce

Table 3: Regression Rate Data for Composition-2, Fuel Grain CompositionParaffin wax -Stearic Acid-Araldite-Hardener-Carbon Black

\begin{tabular}{|c|c|c|c|c|}
\hline \multirow[b]{2}{*}{ No. of Obs. } & \multirow[t]{2}{*}{ Station No. } & \multicolumn{3}{|c|}{ Composition-2 } \\
\hline & & $\begin{array}{c}\text { Average } \\
\text { Thickness in }(\mathrm{mm})\end{array}$ & $\begin{array}{c}\dot{r}_{\text {local }} \\
\text { in }(\mathrm{mm} / \mathrm{sec})\end{array}$ & $\begin{array}{c}\dot{\boldsymbol{r}}_{a v g} \\
\text { in }(\mathrm{mm} / \mathrm{sec})\end{array}$ \\
\hline 1. & 4. & 7.91 & 6.21 & \multirow{14}{*}{5.36} \\
\hline 2. & 5. & 11.42 & 5.51 & \\
\hline 3. & 6. & 10.63 & 5.66 & \\
\hline 4. & 7. & 9.17 & 5.96 & \\
\hline 5. & 8. & 8.14 & 6.16 & \\
\hline 6. & 9. & 11.33 & 5.53 & \\
\hline 7. & 10. & 10.44 & 5.70 & \\
\hline 8. & 11. & 11.05 & 5.58 & \\
\hline 9. & 12. & 11.15 & 5.56 & \\
\hline 10. & 13. & 11.20 & 5.55 & \\
\hline 11. & 14. & 13.39 & 5.12 & \\
\hline 12 & 15. & 11.51 & 5.49 & \\
\hline 13 & 16. & 12.64 & 5.27 & \\
\hline 14 & 17. & 16.40 & 4.52 & \\
\hline
\end{tabular}

Fuel Grain Composition- Paraffin wax -Stearic Acid-Araldite-Hardener-LDPE-EVA-Carbon Black Initial Web Thickness- $37.5 \mathrm{~mm}$

Oxygen Injection Pressure- 300 p.s.i

Firing Duration- $4.625 \mathrm{sec}$ 
Table 4: Regression Rate Data for Composition-3

\begin{tabular}{|c|c|c|c|c|}
\hline \multirow{2}{*}{ No. of Obs. } & Station No. & \multicolumn{2}{|c|}{ Composition-3 } & \multirow{2}{|c|}{$\begin{array}{c}\dot{\boldsymbol{r}}_{\text {avg }} \\
\text { in }(\mathbf{m m} / \mathbf{s e c})\end{array}$} \\
\cline { 3 - 4 } & & $\begin{array}{c}\text { Average } \\
\text { Thickness in }(\mathbf{m m})\end{array}$ & \multirow{2}{*}{4.10} \\
\hline 1. & 3. & 16.79 & 4.47 \\
\hline 2. & 4. & 15.60 & 4.73 \\
\hline 3. & 5. & 15.44 & 4.76 \\
\hline 4. & 6. & 15.97 & 4.66 \\
\hline 5. & 7. & 14.55 & 4.96 \\
\hline 6. & 8. & 17.03 & 4.42 \\
\hline 7. & 9. & 17.38 & 4.35 \\
\hline 8. & 10. & 18.78 & 4.04 \\
\hline 9. & 11. & 17.94 & 4.22 \\
\hline 10. & 12. & 18.71 & 4.06 \\
\hline 11. & 13. & 20.24 & 3.73 \\
\hline 12 & 14. & 20.64 & 3.64 \\
\hline 13 & 15. & 20.22 & 3.73 \\
\hline 14 & 16. & 20.1 & 3.76 \\
\hline 15 & 17. & 21.38 & 3.48 \\
\hline 16 & 18. & 21.15 & 3.53 \\
\hline 17 & 19. & 21.02 & 3.56 \\
\hline 18 & 20. & 20.32 & 3.71 \\
\hline
\end{tabular}

Fuel Grain Composition- Paraffin Wax

Initial Web Thickness- $38.63 \mathrm{~mm}$

Oxygen Injection Pressure- 480 p.s. $i$

Firing Duration- $5.16 \mathrm{sec}$

Table 5: Regression Rate Data for Composition-1

\begin{tabular}{|c|c|c|c|c|}
\hline \multirow{2}{*}{ No. of Obs. } & \multirow{2}{*}{ Station No. } & $\begin{array}{c}|c| \\
\text { Average } \\
\text { Thickness in }(\mathbf{m m})\end{array}$ & $\begin{array}{c}\dot{\boldsymbol{r}}_{\text {local }} \\
\text { in }(\mathbf{m m} / \mathbf{s e c})\end{array}$ & $\begin{array}{c}\dot{\boldsymbol{r}}_{\text {avg }} \\
\text { in }(\mathbf{m m} / \mathbf{s e c})\end{array}$ \\
\hline 1. & 8. & 5.99 & 6.32 & \\
\hline 2. & 9. & 6.70 & 6.18 & \\
\hline 3. & 10. & 8.13 & 5.91 & \multirow{2}{*}{5} \\
\hline 4. & 11. & 8.69 & 5.80 & \multirow{2}{*}{5} \\
\hline 5. & 12. & 9.69 & 5.60 & \multirow{2}{*}{} \\
\hline 6. & 13. & 10.77 & 5.39 & \\
\hline 7. & 14. & 10.75 & 5.40 & \\
\hline 8. & 15. & 10.96 & 5.36 & \\
\hline 9. & 16. & 11.60 & 5.23 & \\
\hline 10. & 17. & 12.02 & 5.15 & \\
\hline
\end{tabular}

Fuel Grain Composition- Paraffin wax -Stearic Acid-Araldite-Hardener-Carbon Black

Initial Web Thickness- $39.03 \mathrm{~mm}$

Oxygen Injection Pressure- 480 p.s.i

Firing Duration- $5.20 \mathrm{sec}$ 
Table 6: Regression Rate Data for Composition-2

\begin{tabular}{|c|c|c|c|c|}
\hline \multirow{2}{*}{ No. of Obs. } & \multirow{2}{*}{ Station No. } & \multicolumn{3}{|l|}{ Composition-2 } \\
\cline { 3 - 4 } & & $\begin{array}{l}\text { Average } \\
\text { Thickness in }(\mathbf{m m})\end{array}$ & $\begin{array}{c}\dot{\boldsymbol{r}}_{\text {local }} \\
\text { in }(\mathbf{m m} / \mathbf{s e c})\end{array}$ & $\begin{array}{c}\dot{\boldsymbol{r}}_{\text {avg }} \\
\text { in }(\mathbf{m m} / \mathbf{s e c})\end{array}$ \\
\hline 1. & 8. & 7.35 & 6.09 & \\
\hline 2. & 9. & 6.88 & 6.18 \\
\hline 3. & 10. & 5.01 & 6.54 \\
\hline 4. & 11. & 5.42 & 6.46 \\
\hline 5. & 12. & 7.73 & 6.01 \\
\hline 6. & 13. & 7.37 & 6.08 \\
\hline 7. & 14. & 8.12 & 5.94 & \multirow{2}{*}{6.14} \\
\hline 8. & 15. & 9.67 & 5.64 \\
\hline 9. & 16. & 8.60 & 5.85 & \\
\hline 10. & 17. & 7.43 & 6.07 \\
\hline 11. & 18. & 7.20 & 6.12 \\
\hline 12 & 19. & 6.67 & 6.22 \\
\hline 13 & 20. & 4.32 & 6.67 & \\
\hline
\end{tabular}

Fuel Grain Composition-Paraffin wax-Stearic Acid-Araldite-Hardener-LDPE-EVA-Carbon Black

Initial Web Thickness- $38.33 \mathrm{~mm}$

Oxygen Injection Pressure- 480 p.s.i

Firing Duration- $3.92 \mathrm{sec}$

Table 7: Regression Rate Data for Composition-3

\begin{tabular}{|c|c|c|c|c|}
\hline \multirow[b]{2}{*}{ No. of Obs. } & \multirow[b]{2}{*}{ Station No. } & \multicolumn{3}{|c|}{ Composition-3 } \\
\hline & & $\begin{array}{c}\text { Average } \\
\text { Thickness in }(\mathrm{mm})\end{array}$ & $\begin{array}{c}\dot{\mathbf{r}}_{\text {local }} \\
\text { in }(\mathrm{mm} / \mathrm{sec})\end{array}$ & $\begin{array}{c}\dot{\mathbf{r}}_{\mathrm{avg}} \\
\text { in }(\mathrm{mm} / \mathrm{sec})\end{array}$ \\
\hline 1. & 3. & 16.79 & 5.49 & \multirow{18}{*}{5.05} \\
\hline 2. & 4. & 15.60 & 5.79 & \\
\hline 3. & 5. & 15.44 & 5.83 & \\
\hline 4. & 6. & 15.97 & 5.70 & \\
\hline 5. & 7. & 14.55 & 6.06 & \\
\hline 6. & 8. & 17.03 & 5.43 & \\
\hline 7. & 9. & 17.38 & 5.34 & \\
\hline 8. & 10. & 18.78 & 4.98 & \\
\hline 9. & 11. & 17.94 & 5.20 & \\
\hline 10. & 12. & 18.71 & 5.00 & \\
\hline 11. & 13. & 20.24 & 4.61 & \\
\hline 12 & 14. & 20.64 & 4.51 & \\
\hline 13 & 15. & 20.22 & 4.61 & \\
\hline 14 & 16. & 20.1 & 4.65 & \\
\hline 15 & 17. & 21.38 & 4.32 & \\
\hline 16 & 18. & 21.15 & 4.38 & \\
\hline 17 & 19. & 21.02 & 4.41 & \\
\hline 18 & 20. & 20.32 & 4.59 & \\
\hline
\end{tabular}


Table 8: Average Regression Rate and Average Mass Consumption Rate of all fuel Compositions at Injection Pressure 300 p.s.i

\begin{tabular}{|l|c|c|c|}
\hline & $\begin{array}{c}\text { Firing Duration in } \\
(\mathbf{s e c})\end{array}$ & $\begin{array}{c}\text { Mass Consumption Rate of the Fuel } \\
\text { in (gm/sec) }\end{array}$ & $\begin{array}{c}\text { Average Regression Rate of the Fuel } \\
\text { in (mm/sec) }\end{array}$ \\
\hline $\begin{array}{l}\text { Composition } \\
1\end{array}$ & 6.071 & 59.66 & 5.07 \\
\hline $\begin{array}{l}\text { Composition } \\
2\end{array}$ & 5.03 & 69.18 & 5.36 \\
\hline $\begin{array}{l}\text { Composition } \\
3\end{array}$ & 4.625 & 36.41 & 4.10 \\
\hline
\end{tabular}

Table 9: Average Regression Rate and Average Mass Consumption

Rate of all Fuel Compositions at Injection Pressure 480 p.s.i

\begin{tabular}{|l|c|c|c|}
\hline & $\begin{array}{c}\text { Firing Duration } \\
\text { in(sec) }\end{array}$ & $\begin{array}{c}\text { mass consumption Rate of the Fuel } \\
\text { in (gm/sec) }\end{array}$ & $\begin{array}{c}\text { Average Regression Rate of the Fuel } \\
\text { in (mm/sec) }\end{array}$ \\
\hline $\begin{array}{l}\text { Composition } \\
1\end{array}$ & 5.16 & 68.91 & 5.48 \\
\hline $\begin{array}{l}\text { Composition } \\
2\end{array}$ & 5.20 & 89.53 & 6.14 \\
\hline $\begin{array}{l}\text { Composition } \\
3\end{array}$ & 3.92 & 43.41 & 5.05 \\
\hline
\end{tabular}

Injection Pressure-300 p.s.i, Firing Duration $6.071 \mathrm{sec}$

Table 10: Variation of Oxidizer Mass Flux along the Grain for Composition-1, at $\dot{m}_{o}=8.235 \mathrm{Kg} / \mathrm{cm}^{2}$-sec

\begin{tabular}{|c|c|c|c|c|}
\hline $\begin{array}{c}\text { Distance } \\
\text { From Head } \\
\text { End in }(\mathbf{c m})\end{array}$ & $\begin{array}{c}\text { Local Regression Rate in } \\
\dot{\boldsymbol{r}}(\mathbf{m m} / \mathbf{s e c})\end{array}$ & $\begin{array}{c}\text { Port Diameter } \\
\text { After Burning } \boldsymbol{D}_{\boldsymbol{p}} \\
\mathbf{i n}(\mathbf{m m})\end{array}$ & $\begin{array}{c}\text { Port Area After } \\
\text { Burning } \boldsymbol{A}_{\boldsymbol{P}}(\mathbf{c m})^{\mathbf{2}}\end{array}$ & $\begin{array}{c}\text { Oxidizer Mass } \\
\text { Flux } \boldsymbol{G}_{\boldsymbol{o x}} \text { in } \\
\left(\mathbf{k g} / \mathbf{c m}^{\mathbf{2}} \text {-sec) }\right.\end{array}$ \\
\hline 0. & 5.74 & 64.75 & 32.92 & 0.25 \\
\hline 2. & 5.28 & 61.96 & 30.15 & 0.27 \\
\hline 4. & 4.85 & 59.36 & 27.67 & 0.29 \\
\hline 6. & 4.90 & 59.65 & 27.94 & 0.29 \\
\hline 8. & 4.89 & 59.64 & 27.93 & 0.29 \\
\hline 10. & 4.90 & 59.65 & 27.94 & 0.29 \\
\hline 12. & 4.89 & 59.91 & 28.18 & 0.29 \\
\hline 14. & 4.96 & 60.03 & 28.05 & 0.29 \\
\hline 16. & 4.92 & 59.77 & 30.23 & 0.27 \\
\hline 18. & 5.29 & 62.05 & 29.95 & 0.27 \\
\hline 20. & 5.24 & 61.76 & & \\
\hline
\end{tabular}

Injection Pressure -300 p.s.i, Firing Duration- $5.03 \mathrm{sec}$

Table 11: Variation of Oxidizer Mass Flux along the Grain for Composition-2, at $\dot{m}_{o}=3.97 \mathrm{Kg} / \mathrm{cm}^{2}$-sec

\begin{tabular}{|c|c|c|c|c|}
\hline $\begin{array}{c}\text { Distance From } \\
\text { Head End in }(\mathbf{c m})\end{array}$ & $\begin{array}{c}\text { Local Regression } \\
\text { Rate in } \dot{\boldsymbol{r}}(\mathbf{m m} / \mathbf{s e c})\end{array}$ & $\begin{array}{c}\text { Port Diameter After } \\
\text { Burning } \boldsymbol{D}_{\boldsymbol{p}} \text { in }(\mathbf{m m})\end{array}$ & $\begin{array}{c}\text { Port Area After } \\
\text { Burning } \boldsymbol{A}_{\boldsymbol{P}}(\mathbf{c m})^{\mathbf{2}}\end{array}$ & $\begin{array}{c}\text { Oxidizer Mass Flux } \\
\boldsymbol{G}_{\boldsymbol{o x}} \mathbf{i n}\left(\mathbf{k g} / \mathbf{c m}^{\mathbf{2}} \text {-sec) }\right.\end{array}$ \\
\hline 0. & 6.21 & 61.24 & 29.45 & 0.13 \\
\hline 1. & 5.51 & 57.73 & 26.17 & 0.15 \\
\hline 2. & 5.66 & 58.52 & 26.89 & 0.14 \\
\hline 3. & 5.96 & 59.98 & 28.25 & 0.14 \\
\hline 4. & 6.16 & 61.01 & 29.23 & 0.13 \\
\hline 5. & 5.53 & 57.82 & 26.25 & 0.15 \\
\hline 6. & 5.70 & 58.71 & 27.07 & 0.14 \\
\hline 7. & 5.58 & 58.1 & 26.51 & 0.14 \\
\hline
\end{tabular}




\begin{tabular}{|c|c|c|c|c|}
\hline \multicolumn{5}{|c|}{ Table 11: Contd,. } \\
\hline 8. & 5.56 & 58.0 & 26.42 & 0.15 \\
\hline 9. & 5.55 & 57.95 & 26.37 & 0.15 \\
\hline 10. & 5.12 & 55.76 & 24.41 & 0.16 \\
\hline 11. & 5.49 & 57.64 & 26.09 & 0.15 \\
\hline 12. & 5.27 & 56.51 & 25.08 & 0.15 \\
\hline 13. & 4.52 & 52.75 & 21.85 & 0.18 \\
\hline 14. & 4.57 & 53.01 & 22.07 & 0.17 \\
\hline 15. & 4.42 & 52.25 & 21.44 & 0.18 \\
\hline 16 & 4.37 & 51.99 & 21.22 & 0.18 \\
\hline
\end{tabular}

Injection Pressure-300 p.s.i,, Firing Duration- $4.625 \mathrm{sec}$

Table 12: Variation of Oxidizer Mass Flux along the Grain for Composition-3, at $\dot{m}_{o}=10.81 \mathrm{Kg} / \mathrm{cm}^{2}$-sec

\begin{tabular}{|c|c|c|c|c|}
$\begin{array}{c}\text { Distance From } \\
\text { Head End in }(\mathbf{c m})\end{array}$ & $\begin{array}{c}\text { Local Regression } \\
\text { Rate in } \dot{\boldsymbol{r}}(\mathbf{m m} / \mathbf{s e c})\end{array}$ & $\begin{array}{c}\text { Port Diameter After } \\
\text { Burning } \boldsymbol{D}_{\boldsymbol{p}} \text { in }(\mathbf{m m})\end{array}$ & $\begin{array}{c}\text { Port Area After } \\
\text { Burning } \boldsymbol{A}_{\boldsymbol{P}}(\mathbf{c m})^{\mathbf{2}}\end{array}$ & $\begin{array}{c}\text { Oxidizer Mass Flux } \\
\boldsymbol{G}_{\boldsymbol{o x}} \mathbf{i n}\left(\mathbf{k g} / \mathbf{c m}^{\mathbf{2}} \text {-sec) }\right.\end{array}$ \\
\hline 0. & 4.47 & 50.81 & 20.27 & 0.53 \\
\hline 1. & 4.73 & 52 & 21.23 & 0.50 \\
\hline 2. & 4.76 & 52.16 & 21.36 & 0.50 \\
\hline 3. & 4.66 & 51.19 & 20.58 & 0.52 \\
\hline 4. & 4.96 & 52.61 & 21.73 & 0.49 \\
\hline 5. & 4.42 & 50.57 & 19.80 & 0.53 \\
\hline 6. & 4.35 & 50.22 & 18.71 & 0.54 \\
\hline 7. & 4.04 & 48.82 & 19.36 & 0.57 \\
\hline 8. & 4.22 & 49.66 & 18.77 & 0.57 \\
\hline 9. & 4.06 & 48.89 & 17.61 & 0.57 \\
\hline 10. & 3.73 & 47.36 & 17.31 & 0.61 \\
\hline 11. & 3.64 & 46.96 & 17.63 & 0.61 \\
\hline 12. & 3.73 & 47.38 & & 0.62 \\
\hline
\end{tabular}

Injection Pressure -480 p.s.i, Firing Duration -5.16 sec

Table 13: Variation of Oxidizer Mass Flux along the Grain for Composition-1, at $\dot{m}_{o}=23.25 \mathrm{Kg} / \mathrm{cm}^{2}$-sec

\begin{tabular}{|c|c|c|c|c|}
\hline $\begin{array}{c}\text { Distance From } \\
\text { Head End in }(\mathbf{c m})\end{array}$ & $\begin{array}{c}\text { Local Regression } \\
\text { Rate in } \boldsymbol{r}(\mathbf{m m} / \mathbf{s e c})\end{array}$ & $\begin{array}{c}\text { Port Diameter After } \\
\text { Burning } \boldsymbol{D}_{\boldsymbol{p}} \text { in }(\mathbf{m m})\end{array}$ & $\begin{array}{c}\text { Port Area After } \\
\text { Burning } \boldsymbol{A}_{\boldsymbol{P}}(\mathbf{c m})^{\mathbf{2}}\end{array}$ & $\begin{array}{c}\text { Oxidizer Mass Flux } \\
\boldsymbol{G}_{\boldsymbol{o x}} \mathbf{i n}\left(\mathbf{k g} / \mathbf{c m}^{\mathbf{2}} \text {-sec) }\right.\end{array}$ \\
\hline 0. & 6.32 & 62.44 & 30.62 & 0.76 \\
\hline 1. & 6.18 & 61.73 & 29.92 & 0.77 \\
\hline 2. & 5.91 & 60.3 & 28.55 & 0.81 \\
\hline 3. & 5.80 & 59.74 & 28.02 & 0.82 \\
\hline 4. & 5.60 & 58.74 & 27.09 & 0.85 \\
\hline 5. & 5.39 & 57.66 & 26.11 & 0.89 \\
\hline 6. & 5.40 & 57.68 & 26.13 & 0.88 \\
\hline 7. & 5.36 & 57.47 & 25.94 & 0.89 \\
\hline 8. & 5.23 & 56.83 & 24.99 & 0.91 \\
\hline 9. & 5.15 & 56.41 & 24.47 & 0.93 \\
\hline 10. & 5.04 & 55.82 & 24.20 & 0.95 \\
\hline 11. & 4.98 & 55.51 & 24.27 & 0.96 \\
\hline 12. & 4.99 & 55.59 & & 0.95 \\
\hline
\end{tabular}

Injection Pressure -480 p.s.i, Firing Duration -5.20 sec 
Table 14: Variation of Oxidizer Mass Flux along the Grain for Composition-2, at $\dot{m}_{o}=23.07 \mathrm{Kg} / \mathrm{cm}^{2}$-sec

\begin{tabular}{|c|c|c|c|c|}
\hline $\begin{array}{c}\text { Distance } \\
\text { From Head } \\
\text { End in }(\mathbf{c m})\end{array}$ & $\begin{array}{c}\text { Local Regression Rate in } \\
\boldsymbol{r}(\mathbf{m m} / \mathbf{s e c})\end{array}$ & $\begin{array}{c}\text { Port Diameter After } \\
\text { Burning } \boldsymbol{D}_{\boldsymbol{p}} \mathbf{i n}(\mathbf{m m})\end{array}$ & $\begin{array}{c}\text { Port Area After } \\
\text { Burning } \boldsymbol{A}_{\boldsymbol{P}}(\mathbf{c m})^{\mathbf{2}}\end{array}$ & $\begin{array}{c}\text { Oxidizer Mass } \\
\text { Flux } \boldsymbol{G}_{\boldsymbol{o x}} \text { in } \\
\left(\mathbf{k g} / \mathbf{c m}^{2} \text {-sec) }\right.\end{array}$ \\
\hline 0. & 6.09 & 61.8 & 29.99 & 0.76 \\
\hline 1. & 6.18 & 61.65 & 29.85 & 0.77 \\
\hline 2. & 6.54 & 63.52 & 31.68 & 0.72 \\
\hline 3. & 6.46 & 63.11 & 31.28 & 0.73 \\
\hline 4. & 6.01 & 60.8 & 29.03 & 0.79 \\
\hline 5. & 6.08 & 61.16 & 29.37 & 0.78 \\
\hline 6. & 5.94 & 60.23 & 28.49 & 0.80 \\
\hline 7. & 5.64 & 58.68 & 27.01 & 0.85 \\
\hline 8. & 5.85 & 59.75 & 28.03 & 0.82 \\
\hline 9. & 6.07 & 60.92 & 29.14 & 0.79 \\
\hline 10. & 6.12 & 61.15 & 29.36 & 0.78 \\
\hline 11. & 6.22 & 61.68 & 29.87 & 0.77 \\
\hline 12. & 6.67 & 64.03 & 32.20 & 0.71 \\
\hline
\end{tabular}

Injection Pressure -480 p.s.i, Firing Duration -3.92 sec

Table 15: Variation of Oxidizer Mass Flux along the Grain for Composition-3, at $\dot{m}_{o}=5.10 \mathrm{Kg} / \mathrm{cm}^{2}$-sec

\begin{tabular}{|c|c|c|c|c|}
\hline $\begin{array}{c}\text { Distance From } \\
\text { Head End in }(\mathbf{c m})\end{array}$ & $\begin{array}{c}\text { Local Regression } \\
\text { Rate in } \dot{\boldsymbol{r}}(\mathbf{m m} / \mathbf{s e c})\end{array}$ & $\begin{array}{c}\text { Port Diameter After } \\
\text { Burning } \boldsymbol{D}_{\boldsymbol{p}} \text { in }(\mathbf{m m})\end{array}$ & $\begin{array}{c}\text { Port Area After } \\
\text { Burning } \boldsymbol{A}_{\boldsymbol{P}}(\mathbf{c m})^{\mathbf{2}}\end{array}$ & $\begin{array}{c}\text { Oxidizer Mass Flux } \\
\boldsymbol{G}_{\boldsymbol{o x}} \mathbf{i n}\left(\mathbf{k g} / \mathbf{c m}^{\mathbf{2}} \text {-sec) }\right.\end{array}$ \\
\hline 0. & 5.49 & 51.54 & 20.86 & 0.24 \\
\hline 1. & 5.79 & 52.73 & 21.83 & 0.23 \\
\hline 2. & 5.83 & 52.89 & 21.97 & 0.23 \\
\hline 3. & 5.70 & 52.36 & 21.53 & 0.23 \\
\hline 4. & 6.06 & 53.78 & 20.66 & 0.24 \\
\hline 5. & 5.43 & 51.3 & 20.38 & 0.25 \\
\hline 6. & 5.34 & 50.95 & 19.28 & 0.26 \\
\hline 7. & 4.98 & 49.55 & 19.94 & 0.25 \\
\hline 8. & 5.20 & 50.39 & 19.33 & 0.26 \\
\hline 9. & 5.00 & 49.62 & 17.86 & 0.28 \\
\hline 10. & 4.61 & 48.09 & 18.17 & 0.28 \\
\hline 11. & 4.51 & 47.69 & 18.26 & 0.28 \\
\hline 12. & 4.61 & 48.11 & 17.31 & 0.27 \\
\hline 13. & 4.65 & 48.23 & 17.48 & 0.29 \\
\hline 14. & 4.32 & 46.95 & 17.57 & 0.29 \\
\hline 15. & 4.38 & 47.18 & 18.10 & 0.29 \\
\hline 16. & 4.41 & 47.31 & & 0.28 \\
\hline 17. & 4.59 & 48.01 & & \\
\hline
\end{tabular}

\section{CONCLUSIONS}

In the present investigation, an initiative has been taken to improve the mechanical properties of paraffin wax by the addition of certain additives like stiffening agents like stearic acid, Araldite, hardener, different types of polyethylene. The propellant compositions thus prepared were subjected to stress-strain analysis and combustion parameter study. The following conclusions have been drawn from the study:

- Further from the analysis of mechanical properties, it is seen that the tensile strength and young modulus for these samples are in order of sample. $3>$ sample. $1>$ sample. 2 . 
- The highest Young modulus has been observed for sample 3.

- The flexural strength of the wax with different additives was improved.

- The tensile strength of the wax with additives was double in value than the wax used for this study.

- Young's modulus of the wax with additives was increased by $116.62 \mathrm{MPa}$ in value.

- By adding LDPE, EVA the total elongation \& uniform elongation have improved by 5 times and 3 times respectively. This will indicate that the brittle nature of wax was decreased by adding additives. It will reduce the tendency of bending, necking of the wax significantly.

- The calorific value of virgin PW, PW- Stearic Acid- Araldite -Hardener-LDPE-EVA- Carbon Black are similar. The calorific value of P.W- Stearic Acid- Araldite -Hardener- Carbon Black is of greater value as compared to paraffin wax. Calorific values of the samples are improved by adding additives.

- Increment in the value of regression rates with different composition changes in the order of sample-1> sampl. $2>$ sample. 3 at both of the oxygen injection pressure. Further from the analysis of mechanical properties, it is seen that the tensile strength and young modulus for these samples are in order of sample.3> $\square \square \square \square \square \square .1>$ $\square \square \square \square \square \square .2$. These results suggest that the composition which has higher mechanical strength has a lower regression rate and the composition with lower mechanical strength has a higher regression rate. But for all these three samples the regression rate is of the range $4 \mathrm{~mm}$ to $6 \mathrm{~mm}$ which is much higher than the conventional hybrid fuel regression rate.

\section{REFERENCES}

1. Bartel, H.R, and Rannie, W.D., "Solid Fuel Combustion as applied to Ramjets", Progress report, Jet propulsion Laboratory, California Institute of Technology, September 1964, pp.3-12.

2. Penner, S.S, “Chemical Rocket Propulsion and Combustion Research”, Gordon and Breach, New York, 1962, pp.145-153

3. Shunmugasundaram, M., et al. "An optimization of processparameters for stircast aluminium metal matrix composites to improvematerialremoval rate." Int. J. Mech. Prod. Eng. Res. Develop. 9 (2019): 951-960.

4. Green Jr. L., "Introductory Consideration on Hybrid Rocket Combustion”, Progress in Aeronautics and Astronautics, AIAA, New York, Vol.15, 1964, pp.451-484.

5. Deepak, D., and Beedu Rajendra. "Investigation of the effect of processparameters on materialremoval rate in machining of is 5986 fe 410 steel by wire-edm: the Optimization and regressionmodeling." International Journal of Mechanical and Production Engineering Research and Development 9.6 (2019): 411-420.

6. Houser, T.J., and Peck, M.V., “ Research in Hybrid Combustion”, Progress in Aeronautics and Astronautics, AIAA, New York, Vol.15, 1964, pp.559-581.

7. Karabeyoglu, M.A., Cantwell, B.J., and Altman, D., "Development and Testing of Paraffin-Hybrid Rocket Fuels”, AIAA, July 2001, pp.2001-4503 paper

8. Hashem, Somaya, et al. "A simple multilinearregression model for predictingfibrosis scores in chronicEgyptianhepatitis $C$ virus patients." International Journal of Bio-Technology and Research 4.3 (2014): 37-46. 
9. Marxman, G., and Gilbert, M., “Turbulent Boundary Layer Combustion in Hybrid Rocket”, Ninth Symposium (International) on Combustion, Academic Press New York, 1963, pp.371-372.

10. Ramhalli, K. and Stickler, D. B., "Combustion of Hydrogen-Nitrogen Mixtures in Turbulent Boundary Layer and the Role of Chemical Kinetics, " pp. 961-979, HydrogenEnergy Progress IV, Pergammon Press, 1982.

11. Karthik, K., et al. "Optimization of the ProcessParameter in Drilling of GFRP using HSS Drill." Int. J. Mech. Prod. Eng. Res. Develop. 7.6 (2017).

12. P. N. Estey, D. Altman, and J. S. McFarlane, “An evaluation of scaling effects for hybrid rocket motors," in Proceedings ofthe 27th Joint Propulsion Conference(AIAA/SAE/ASME '91),Sacramento, Calif, USA, June 1991, AIAA Paper 91-2517.

13. Sarigul-Klijn, N., et al. "Air Launching Earth-to-Orbit Vehicles: Delta V gains from Launch Conditions and Vehicle Aerodynamics, " AIAA Paper 2004-872, Jan 2004.

14. Jacob, Eric J., "Nonlinear Combustion Instability Generalized Framework," Ph.D. Dissertation, Department of Aerospace Engineering, The University of Tennessee Knoxville, TN, 2009.

15. Raza, Hasan, SamreenHena, and Atiya Saeed. "The effects of Interest rate, on savings and deposits in Pakistan." International Journal of Business and General Management (IJBGM) 6.6 (2017): 67-74.

16. Lee, C., Lee, J. W., and Byun, D. Y., "Transient Analysis of Hybrid Rocket Combustion by the Zeldovich-Novozhilov Method," KSME International Journal, Vol.17, No. 10, 2003, pp. 1572-1582.

17. Karabeyoglu, M.A., Zillac, G., Cantwell, B.J., De Zilwa, S.R.N., and Castelucci, P., "Scale-up Tests of High Regression Rate Paraffin-Based Hybrid Rocket Fuels", Journal of Propulsion and Power, Vol.20, No.6, November-December 2004, pp. 10371045

18. Odah, MeshalHarbi, Ali SadigMohommedBager, and Bahr Kadhim Mohammed. "Studying the determinants of divortiality in Iraq. A two-stage estimation model withtobitregression." International Journal of AppliedMathematics\&Statistical Sciences 7.2 (2018): 45-54.

19. Wilson. Edmond W., Keller Bretl D., Haknes Kellen M., Smeal Christopher S., and Easterly Megan S., "Ultraviolet-Visible Spectrometry Characterization of Combustion in Hybrid Rocket Motor", 42 ${ }^{\text {nd }}$ AIEE/ASME/SAE/ASEE Joint Propulsion Conference \& Exhibit, July 2006, pp. 9-12

20. Moutet, A., and Barrere, M., "Les Fuses a Lithergol on Fuses Hybrids”, Rech. Aeron., Vol. 75, 1960, pp. 23-25.

21. Karabeyoglu, M.A., Cantwell, B.J. and Altman, D., 2001, "Development and Testing of Paraffn-Based Hybrid RocketFuels", in Proceedings of the 37th AIAA/ASME/SAE/ASEEJoint Propulsion Conference and Exhibit, July 2001, AIAA Paper2001-4503.

22. Green, L., Jr., "Introductory Consideration on Hybrid Rocket Combustion," Progress inAstronautics and Aeronautics, Vol. 15, Heterogeneous Combustion. p. 45 1, AcademicPress, 1964

23. Fineman, S., “Some Analytical Consideration of the Hybrid Combustion Problem”, MS. Thesis, Princeton University, 1962.

24. George, P.; Krishnan, S.; Varkey, P.M.; Ravindran, M. \& Lalitha, $R$. "Fuel regression rate in hydroxyl terminatedpolybutadiene/gaseous-oxygen hybrid rocket motors”. J.Propul. Power, 2001, 17(1), 35-42.

25. Soojong Kim, Jungpyo Lee, Heejang Moon, Jinkon Kim, Honggye Sung and Oh Chae Kwon "Regression Characteristics of the Cylindrical Multiport Grain in Hybrid Rockets", JOURNAL OF PROPULSION AND POWER Vol. 29, No. 3, May-June 2013 . 
26. Martin J. Chiaverini, George C. Harting, Yeu-Cherng Lu, Kenneth K. Kuo, Arie Peretz, H. Stephen Jones,Brian S. Wygle, and Joseph P. Arves, "Pyrolysis Behavior of Hybrid-Rocket Solid Fuels Under Rapid Heating Conditions”, Journal of Propulsion and Power Vol. 15, No. 6, November-December 1999

27. Tamura, T., Yuasa, S. and Yamamoto, K.," Effects of Swirling Oxidizer Flow on Fuel Regression. Rate of Hybrid Rockets", 35th AIAALASME/SAE/ASEE Joint Propulsion 'Conference and Exhibit 20-24 June 1999 Los Angeles, California

28. Vasily Novozhilov, Paul Joseph, Keiichi Ishiko, Toru Shimada, Hui Wangand Jun Liu, "Polymer Combustion as a Basis for Hybrid Propulsion: A Comprehensive Review and New Numerical Approaches", Energies 2011, 4, 1779-1839; doi:10.3390/en4101779.

29. E. J. Wernimont and S. D. Heister "Combustion Experiments in Hydrogen Peroxide/Polyethylene Hybrid Rocket with Catalytic Ignition”, JOURNAL OF PROPULSION AND POWER Vol. 16, No. 2, March-April 2000.

30. Zachary Dunn, Jonny Dyer, Kevin Lohner and Eric Doran Cedric Bayar and Andy Sadhwani, "Test Facility Development for the 15,000 lb Thrust Peregrine Hybrid Sounding Rocket”, 43rd AIAA/ASME/SAE/ASEE Joint Propulsion Conference \& Exhibit 8 - 11 July 2007, Cincinnati, $\mathrm{OH}$.

31. Daniel B. Larson, Eric Boyer, Trevor Wachs, and Kenneth K. Kuo, John D. DeSain, Thomas J. Curtiss, and Brian B. Brady, "Characterization of the Performance of Paraffin / LiAlH4 Solid Fuels in a Hybrid Rocket System", 47th AIAA/ASME/SAE/ASEE Joint Propulsion Conference \& Exhibit 31 July - 03 August 2011, San Diego, California. 
